\title{
Intestinal fermentation in patients with self-reported food hypersensitivity: painful, but protective?
}

This article was published in the following Dove Press journal:

Clinical and Experimental Gastroenterology

3 July 2010

Number of times this article has been viewed

\author{
Jørgen Valeur ${ }^{1,2}$ \\ Mette Helvik Morken' \\ Elisabeth Norin ${ }^{3}$ \\ Tore Midtvedt ${ }^{3}$ \\ Arnold Berstad ${ }^{1,2}$ \\ 'Institute of Medicine, University \\ of Bergen, Bergen, Norway; \\ ${ }^{2}$ Department of Medicine, Haukeland \\ University Hospital, Bergen, Norway; \\ ${ }^{3}$ Department of Microbiology, Tumor \\ and Cell Biology, Karolinska Institutet, \\ Stockholm, Sweden
}

Purpose: Enterometabolic disturbances may cause meal-related symptoms. We performed a functional evaluation of the intestinal microflora in patients with unexplained, self-reported food hypersensitivity by measuring fecal short-chain fatty acids (SCFAs).

Patients and methods: Thirty-five consecutive patients with self-reported food hypersensitivity and 15 healthy volunteers of similar age, gender, and body mass index collected all feces for 72 hours. Fecal concentrations of acetic, propionic, $n$-butyric, $i$-butyric, $n$-valeric, $i$-valeric, $n$-caproic, and $i$-caproic acids were analyzed by gas-liquid chromatography. Concentrations and excretions (output) of SCFAs in patients and controls were compared and related to gastrointestinal symptoms.

Results: Despite nonsignificant differences between patients and controls for both total and individual SCFA concentrations and excretions, $n$-butyric acid comprised a higher $(P=0.035)$ and acetic acid a lower $(P=0.012)$ proportion of total SCFA in patients compared to controls. There were no significant correlations between symptom scores and concentrations or excretions of individual or total SCFAs, but the proportion of $n$-butyric acid was significantly higher in patients with severe symptoms compared to patients with moderate symptoms $(P=0.016)$.

Conclusion: The results indicate an enterometabolic disturbance in patients with self-reported food hypersensitivity. Higher proportions of $n$-butyric acid may be related to abdominal symptom generation, but may also protect against organic bowel disease. Further studies are needed to clarify these aspects.

Keywords: butyrate, dysbiosis, gut microbiota, irritable bowel syndrome, short-chain fatty acids

\section{Introduction}

Unexplained, self-reported food hypersensitivity is a prevalent, but poorly understood condition. ${ }^{1}$ Most of the patients present symptoms compatible with irritable bowel syndrome (IBS), and altered metabolic activity of the intestinal microflora has been postulated as a cause. ${ }^{2}$ Conceivably, "malfermentation" of food residues entering the colon may explain why intake of poorly absorbable foods provokes IBS-like complaints. ${ }^{3}$ Thus, ingestion of the undigestible carbohydrate lactulose replicates abdominal symptoms in many patients with self-reported food hypersensitivity. ${ }^{4}$ Evidence that implicate the microbiota in the pathogenesis of functional gastrointestinal disorders is indeed emerging. ${ }^{5}$

The gut microbial community can be evaluated either by assessing its composition or by measuring its functions. The term microflora associated characteristics (MAC) has been introduced to designate the latter approach, being defined as the recording
Correspondence: Jørgen Valeur Institute of Medicine, University of Bergen, Haukeland University Hospital, NO-502I Bergen, Norway

Tel +4755977980

Fax +47559975890

Email jorgen.valeur@med.uib.no (c) 20IOValeur et al, publisher and licensee Dove Medical Press Ltd. This is an Open Access article which permits unrestricted noncommercial use, provided the original work is properly cited. 
of any anatomical structure or physiological, biochemical, or immunological function in a macroorganism, which has been influenced by the microflora in either an anabolic or catabolic way. ${ }^{6}$ Measurement of fecal short-chain fatty acids (SCFAs) is a recognized MAC and was utilized in the present study to explore whether patients with self-reported food hypersensitivity display abnormal microflora-related functions.

\section{Material and methods Patients and controls}

Patients referred to Haukeland University Hospital for investigation of abdominal complaints self-attributed to food hypersensitivity were recruited consecutively from February 2008 to March 2009. They were thoroughly examined, and food allergies and other organic gastrointestinal diseases were ruled out by methods as described previously. ${ }^{7}$ Exclusion criteria were age below 18 years, pregnancy/ lactation, organic gastrointestinal disease, and prior use of antibiotics (past month). Patients were diagnosed with IBS according to the Rome II criteria, and gastrointestinal symptoms were scored (from 0 to 500) using a translated version of the irritable bowel symptom-severity scoring system (IBS-SSS), developed by Francis et al. ${ }^{8}$ In addition, patients were asked whether constipation or diarrhea was their most bothersome symptom. Healthy volunteers were recruited from the hospital staff and students at the University of Bergen. They were included if they considered themselves to be healthy, and were not further examined. They were excluded if they had used antibiotics during the past month. The study was performed in accordance with the Declaration of Helsinki and approved by the Regional Committee for Medical Research Ethics.

\section{Fecal sampling procedure}

The participants collected all feces that passed during a $72 \mathrm{~h}$ period, using one plastic box per day (volume $1000 \mathrm{~mL}$; diameter 133 mm; reg. codes 257077 and 257078, Corporate Express, Oslo, Norway). They were carefully instructed to freeze the specimens immediately at $-20^{\circ} \mathrm{C}$ at home, and bring the frozen boxes to the hospital. Total ( $72 \mathrm{~h}$ ) fecal wet weight was noted, and a small piece of feces from each box was retained for SCFA measurement (stored at $-20^{\circ} \mathrm{C}$ until analysis).

\section{SCFA analysis}

SCFA analyses were performed at Karolinska Institutet, Stockholm, Sweden. The fecal material was homogenized after addition of distilled water containing $3 \mathrm{mmol} / \mathrm{L}$ of 2-ethylbutyric acid (as internal standard) and $0.5 \mathrm{mmol} / \mathrm{L}$ of $\mathrm{H}_{2} \mathrm{SO}_{4} ; 2 \mathrm{~mL}$ of the homogenate was vacuum distilled, according to the method of Zijlstra et al, ${ }^{9}$ as modified by Höverstad et al. ${ }^{10}$ The distillate was analyzed with gas-liquid chromatography and quantified using internal standardization. Flame ionization detection was employed. The results were expressed in $\mathrm{mmol} / \mathrm{kg}$ wet weight. The following SCFAs were analyzed: acetic, propionic, $i$-butyric, $n$-butyric, $i$-valeric, $n$-valeric, $i$-caproic, and $n$-caproic acids. A mean value based on the number of samples delivered was calculated for each subject and used for the statistical analyses.

\section{Statistics}

Data were analyzed using Graphpad Prism version 5 (Graphpad Software Inc., San Diego, CA, USA). Data are expressed as mean \pm standard deviation (SD), unless otherwise stated. We used unpaired $t$-tests to compare mean values between the groups. Categorical data were compared using Fisher's exact test. Correlations were evaluated using Pearson's correlation coefficient. All tests were two-tailed, and $P$ values of less than $5 \%$ were considered statistically significant.

\section{Results Subject characteristics}

Forty-seven patients were referred to our hospital during the recruitment period. Eleven patients (3 males [M], 8 females $[\mathrm{F}]$ ) refused to participate in the study (they felt that the procedure was too cumbersome), and one 17 year old male patient was too young to be included. A total of 35 patients were therefore studied ( $5 \mathrm{M}, 30 \mathrm{~F}$; mean age 36.2 , range 18-67 years; mean body mass index (BMI) 24.7, range $\left.16.2-41.0 \mathrm{~kg} / \mathrm{m}^{2}\right)$. Fifteen healthy volunteers agreed to participate (4 M, $11 \mathrm{~F}$; mean age 32.1, range 22-68 years; mean BMI 23.7, range 20.1-27.8 kg/m²). Patients and controls were comparable with respect to gender, age, and BMI. None of the patients had evidence of food allergies or other organic diseases that could explain their symptoms. All patients except one male (who had abdominal pain that was unrelated to changes in stool frequency or stool form), fulfilled the Rome II criteria for having IBS. Mean habitual symptom score (IBS-SSS) in patients was $280.5 \pm 87.4$, and according to the suggested cut-off values, ${ }^{8}$ respectively 19 and 16 patients could be classified as moderate (score 175-300) and severe (score $>300$ ) cases. Twelve $(34.3 \%)$ and 20 patients $(57.1 \%)$, respectively, claimed that constipation and diarrhea was their predominant bowel disturbance, whereas the rest $(n=3 ; 8.6 \%)$ could not decide which was worse. 


\section{Fecal samples}

The $72 \mathrm{~h}$ fecal collection procedure was successfully completed by all participants, except in two controls, who collected feces for one day ( $24 \mathrm{~h}$ ) only. Most of the subjects (27 patients and seven controls) passed feces daily, while some voided only two of three days (four patients and four controls), and some only once (four patients and two controls). Mean fecal wet weight $(72 \mathrm{~h}$ ) was $417.2 \pm 226.6 \mathrm{~g}$ in patients and $442.3 \pm 244.4 \mathrm{~g}$ in controls $(P=0.7)$. Interestingly, all patients who reported that constipation was their predominant bowel disturbance $(n=12)$ passed feces daily during the collection period, and fecal weight was not significantly different between patients complaining of predominant constipation and patients complaining of predominant diarrhea (370.7 $\pm 297.4 \mathrm{~g}$ versus $447.8 \pm 156.0 \mathrm{~g} ; P=0.3)$.

\section{Fecal SCFAs}

Total SCFA concentration in feces varied considerably from day to day within individuals, with estimated intra-individual coefficients of variation being $22.6 \%$ and $20.6 \%$ for patients and controls respectively. Inter-individual coefficients of variation were even greater; $56.2 \%$ and $42.2 \%$ for patients and controls respectively. Acetic, propionic, and $n$-butyric acids were the dominating SCFAs in all subjects. Iso-caproic acid was detectable in 11 patients and five controls, whereas $n$-caproic acid was absent in one patient and one control. There were no significant differences in either concentrations or excretions (output) between patients and controls (Table 1). There were several significant correlations between the individual SCFA concentrations (data not shown), similar to what has been reported previously. ${ }^{11,12}$ Neither BMI nor fecal wet weight was significantly correlated to SCFA concentrations, and there was no difference between males and females. There was no difference in SCFA concentrations or excretions between patients complaining of predominant constipation and patients complaining of predominant diarrhea. There was no correlation between individual or total SCFA concentrations or excretions and symptom scores in the patient group. Interestingly, the proportional distribution of individual SCFA to total SCFA was different between

Table I Fecal SCFAs in patients with self-reported food hypersensitivity and healthy controls

\begin{tabular}{|c|c|c|c|}
\hline SCFA concentration (mmol/kg wet weight) & Patients $(n=35)$ & Controls $(n=15)$ & $P$ value \\
\hline Acetic acid & $86.84 \pm 59.08$ & $107.30 \pm 53.46$ & 0.25 \\
\hline$\%$ of total SCFA concentration & $69.37 \pm 9.21$ & $76.91 \pm 9.56$ & $0.01 *$ \\
\hline Propionic acid & $11.53 \pm 6.44$ & $9.71 \pm 3.28$ & 0.31 \\
\hline$\%$ of total SCFA concentration & $10.37 \pm 3.52$ & $8.46 \pm 3.70$ & 0.09 \\
\hline i-butyric acid & $1.80 \pm 0.82$ & $1.47 \pm 0.47$ & 0.15 \\
\hline$\%$ of total SCFA concentration & $1.89 \pm 0.94$ & $1.38 \pm 0.67$ & 0.06 \\
\hline n-butyric acid & $|4.9| \pm 9.32$ & $11.32 \pm 5.58$ & 0.17 \\
\hline$\%$ of total SCFA concentration & $13.12 \pm 5.76$ & $9.47 \pm 4.60$ & $0.04^{*}$ \\
\hline$i$-valeric acid & $2.43 \pm 1.20$ & $2.03 \pm 0.71$ & 0.23 \\
\hline$\%$ of total SCFA concentration & $2.71 \pm 1.54$ & $2.05 \pm 1.22$ & 0.15 \\
\hline$n$-valeric acid & $1.77 \pm 1.01$ & $1.45 \pm 0.45$ & 0.25 \\
\hline$\%$ of total SCFA concentration & $1.80 \pm 0.94$ & $\mathrm{I} .34 \pm 0.76$ & 0.10 \\
\hline$i$-caproic acid & $0.03 \pm 0.06$ & $0.02 \pm 0.03$ & 0.27 \\
\hline$\%$ of total SCFA concentration & $0.03 \pm 0.05$ & $0.01 \pm 0.03$ & 0.27 \\
\hline n-caproic acid & $0.70 \pm 0.92$ & $0.42 \pm 0.53$ & 0.31 \\
\hline$\%$ of total SCFA concentration & $0.70 \pm 0.81$ & $0.38 \pm 0.53$ & 0.16 \\
\hline Total SCFA & $120.00 \pm 67.40$ & $133.80 \pm 56.48$ & 0.49 \\
\hline SCFA excretion (mmol/72 h) & Patients $(n=35)$ & Controls $(n=13)$ & $P$ value \\
\hline Acetic acid & $39.07 \pm 35.33$ & $48.08 \pm 47.19$ & 0.48 \\
\hline Propionic acid & $5.31 \pm 4.70$ & $4.40 \pm 3.44$ & 0.53 \\
\hline i-butyric acid & $0.76 \pm 0.53$ & $0.57 \pm 0.32$ & 0.25 \\
\hline n-butyric acid & $6.72 \pm 5.71$ & $5.61 \pm 5.35$ & 0.55 \\
\hline i-valeric acid & $1.00 \pm 0.67$ & $0.77 \pm 0.31$ & 0.23 \\
\hline$n$-valeric acid & $0.76 \pm 0.64$ & $0.61 \pm 0.36$ & 0.44 \\
\hline$i$-caproic acid & $0.02 \pm 0.03$ & $0.01 \pm 0.01$ & 0.27 \\
\hline$n$-caproic acid & $0.29 \pm 0.46$ & $0.17 \pm 0.19$ & 0.37 \\
\hline Total SCFA & $53.92 \pm 44.23$ & $60.23 \pm 55.15$ & 0.68 \\
\hline
\end{tabular}

Notes: Data are presented as mean \pm SD.

*Denotes statistically significant differences between patients and controls. 
patients and controls, with a significantly lower percentage of acetic acid $(P=0.012)$ and higher percentage of $n$-butyric acid in the patients $(P=0.035)$. Although there was no correlation between the percentage of acetic acid or $n$-butyric acid and symptom scores, the proportion of $n$-butyric acid was higher in patients classified as severe cases according to IBS-SSS than in patients classified as moderate cases $(P=0.016)$ (Figure 1).

\section{Discussion}

The appearance of SCFAs in feces reflects a complex interplay between host, diet, and microbes, and an altered SCFA profile may signify enterometabolic changes that could be related to functional gastrointestinal symptoms, either as a cause or a consequence. In the present study, patients with unexplained, self-reported food hypersensitivity and abdominal complaints had higher proportions of $n$-butyric acid and lower proportions of acetic acid in fecal samples than healthy controls. These data are partly analogous to findings in patients with IBS reported by other groups, ${ }^{13,14}$ although not all. ${ }^{15,16}$ In the following section, possible implications of our results are discussed.

Weaver et $\mathrm{al}^{17}$ argue that ratios of individual SCFA concentrations to total SCFA concentration are better indicators of microbial fermentation patterns than absolute quantities due to variations in the liquid content of samples. In healthy volunteers, concentrations of the major SCFAs correlate positively with fecal water content. ${ }^{12}$ This may be explained by variations in intestinal transit time, as a rapid passage could impair absorption of both water and SCFAs. This view is supported by El Oufir et al. ${ }^{18}$ Also, the recently reported association between obesity and high total SCFA concentration ${ }^{19}$ may be explained by decreased intestinal

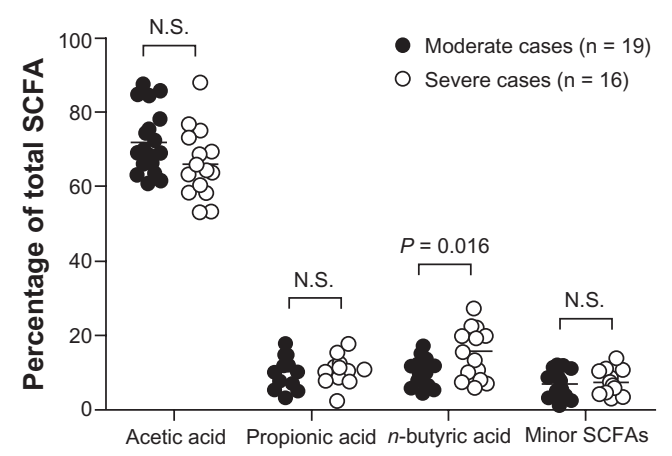

Figure I SCFA distribution in fecal samples from patients classified as moderate cases $(n=19)$ and patients classified as severe cases $(n=16)$. Individual SCFA are shown as mean percentages of total SCFA concentration. Note, the proportion of $n$-butyric acid is higher in severe cases versus moderate cases $(P=0.016)$. Minor SCFAs $=$ sum of percentages of $i$-butyric, $i$-valeric, $n$-valeric, $i$-caproic, and $n$-caproic acids. transit time. ${ }^{20}$ The relationship between fecal water content and SCFA concentration does not apply for all conditions, however, as antibiotic-associated diarrhea is characterized by low levels of SCFA concentrations due to suppressed microbial fermentation. ${ }^{21}$ Mortensen et a ${ }^{22}$ demonstrated that IBS patients with constipation have low fecal SCFA concentrations and IBS patients with diarrhea have high fecal SCFA concentrations. That fecal weights and SCFA concentrations in our study were similar between patients complaining of predominant constipation and patients complaining of predominant diarrhea is therefore interesting, and may question the validity of the patients' claims about bowel habits. ${ }^{23}$ Constipation and diarrhea should be considered as signs rather than symptoms, and our results demonstrate the value of quantifying stool weight objectively. In the present study, neither fecal wet weight nor BMI was significantly related to SCFA concentrations. Hence, it seems unlikely that the different SCFA proportions found between patients and controls in our study could be explained by differences in intestinal transit times solely.

Acetic, propionic, and $n$-butyric acids are mainly derived from proximal colonic fermentation of carbohydrates escaping small intestinal digestion and absorption. That dietary carbohydrates plays an important role in yielding SCFAs was convincingly demonstrated in a recent study by Duncan et al, ${ }^{24}$ showing a marked reduction of both butyrate and butyrogenic bacteria in fecal samples from obese individuals after introduction of a carbohydrate restricted diet. Malabsorption of starch, in particular, shifts the SCFA distribution in favor of $n$-butyric acid. ${ }^{25}$ The ability to digest and absorb starch shows marked inter-individual variation, possibly on a genetic basis, ${ }^{26}$ but whether patients with selfreported food hypersensitivity malabsorb more starch than healthy individuals is presently unknown. Conceivably, aberrations of small intestinal motility, such as rapid small intestinal transit induced by psychological stress ${ }^{27}$ and possibly atopic "IgE arming" of intestinal mast cells,${ }^{28}$ may increase colonic delivery of undigested starch. Also, deficiency of alpha glucosidase has been suggested as a putative cause of IBS, ${ }^{29}$ but the finding has not been followed up in proper studies. We acknowledge that the results of our study, ie, high proportions of $n$-butyric acid and low proportions of acetic acid in fecal samples from patients with self-reported food hypersensitivity, could reflect dietary differences between patients and controls. However, we have previously demonstrated that patients with self-reported food hypersensitivity eat similar amounts of whole grain bread, fruit, and raw vegetables as healthy controls. ${ }^{30}$ 
Our results, indicating altered intestinal fermentation, are consistent with an enterometabolic disturbance in patients with self-reported food hypersensitivity, conceivably associated with IBS-like symptoms. There is evidence that the intestinal microflora is altered in IBS patients compared to controls. ${ }^{31}$ Decreased numbers of lactobacilli and bifidobacteria have been reported, ${ }^{32}$ and, interestingly, neither of these genera are capable of producing $n$-butyric acid. ${ }^{33,34}$ These observations are compatible with our finding of increased proportions of $n$-butyric acid in fecal samples. In animal models, $n$-butyric acid may be directly involved in symptom generation, ${ }^{35}$ although preliminary human studies does not support this view. ${ }^{36}$ That neither concentrations or excretions, nor percentages of any of the analyzed SCFAs, were correlated to symptom scores in our study seems to argue against a direct effect of SCFAs. Still, patients classified as severe cases had higher values of $n$-butyric acid in relation to total SCFA than patients with less symptoms a finding in accordance with data from other groups. ${ }^{37}$ The results of a "butyrogenic" diet trial in IBS patients are eagerly awaited. ${ }^{38}$

Intriguingly, high proportions of $n$-butyric acid may protect against organic bowel diseases, both inflammatory and neoplastic. ${ }^{39}$ Regulation of gene expression through inhibition of histone deacetylase seem to be an important mechanism whereby butyrate exert immuno-modulatory and anticarcinogenic effects. ${ }^{39}$ Although most of our knowledge concerning the protective role of $n$-butyric acid is based on animal and in vitro studies, lower proportions of $n$-butyric acid and higher proportions of acetic acid have been demonstrated in enema samples from patients with adenomatous polyps and colonic cancer compared to healthy controls. ${ }^{17}$ Importantly, Chey et $\mathrm{al}^{40}$ recently observed a considerably lower prevalence of colorectal adenomas in IBS patients compared to asymptomatic controls. In this regard, and based on our results, it is tempting to speculate that having IBS is actually advantageous. Whether IBS has a protective effect against organic bowel diseases - via intestinal microbiota skewed to produce $n$-butyric acid certainly deserves to be investigated further.

\section{Conclusion}

We conclude that the fecal SCFA profile seems to be altered in patients with unexplained, self-reported food hypersensitivity. This may reflect considerable alterations in the intestinal microflora. High proportions of $n$-butyric acid are conceivably related to abdominal symptom generation, but may at the same time offer protection against colorectal inflammation and neoplasia. These aspects should be addressed in future studies.

\section{Acknowledgments/disclosure}

The work was supported by a research grant from the Western Norway Regional Health Authority. We thank Tove Berstad, Aud-Sissel Hjartholm, Ragna Lind, Nathalie Puaschitz, and Anna Karin Persson for invaluable technical assistance. The authors report no conflicts of interest in this work.

\section{References}

1. Berstad A, Arslan G, Lind R, Florvaag E. Food hypersensitivityimmunologic (peripheral) or cognitive (central) sensitization? Psychoneuroendocrinology. 2005;30(10):983-989.

2. Hunter JO. Food allergy - or enterometabolic disorder? Lancet. 1991; 338(8765):495-496.

3. Madden JA, Hunter JO. A review of the role of the gut microflora in irritable bowel syndrome and the effects of probiotics. Br J Nutr. 2002; 88 Suppl 1:S67-S72.

4. Valeur J, Morken MH, Norin E, Midtvedt T, Berstad A. Carbohydrate intolerance in patients with self-reported food hypersensitivity: comparison of lactulose and glucose. Scand J Gastroenterol. 2009;44(12): 1416-1423.

5. Collins SM, Bercik P. The relationship between intestinal microbiota and the central nervous system in normal gastrointestinal function and disease. Gastroenterology. 2009;136(6):2003-2014.

6. Midtvedt T, Björneklett A, Carlsten-Duke B, et al. The influence of antibiotics upon microflora associated characteristics in man and animals. In: Wostman BS, editor. Germfree Research: Microflora Control and its Application to the Biochemical Sciences. Progress in Clinical and Biological Research. New York: Alan R Liss Corporation; 1985:241-244.

7. Valeur J, Øines E, Morken MH, Holst JJ, Berstad A. Plasma glucagonlike peptide 1 and peptide YY levels are not altered in symptomatic fructose-sorbitol malabsorption. Scand J Gastroenterol. 2008;43(10): 1212-1218.

8. Francis CY, Morris J, Whorwell PJ. The irritable bowel severity scoring system: a simple method of monitoring irritable bowel syndrome and its progress. Aliment Pharmacol Ther. 1997;11(2):395-402.

9. Zijlstra JB, Beukema J, Wolthers BG, Byrne BM, Groen A, Dankert J. Pretreatment methods prior to gaschromatographic analysis of volatile fatty acids from faecal samples. Clin Chim Acta. 1977;78(2): 243-250.

10. Hoverstad T, Fausa O, Bjorneklett A, Bohmer T. Short-chain fatty acids in the normal human feces. Scand J Gastroenterol. 1984;19(3): 375-381.

11. Cardona ME, Collinder E, Stern S, Tjellström B, Norin E, Midtvedt T. Correlation between fecal iso-butyric and iso-valeric acids in different species. Microb Ecol Health Dis. 2005;17(3):177-182.

12. Siigur U, Norin KE, Allgood G, Schlagheck T, Midtvedt T. Concentrations and correlations of faecal short-chain fatty acids and faecal water content in man. Microb Ecol Health Dis. 1994;7(6):287-294.

13. Kopecny J, Simunek J. Cellulolytic bacteria in human gut and irritable bowel syndrome. Acta Vet Brno. 2002;71:421-427.

14. Treem WR, Ahsan N, Kastoff G, Hyams JS. Fecal short-chain fatty acids in patients with diarrhea-predominant irritable bowel syndrome: in vitro studies of carbohydrate fermentation. J Pediatr Gastroenterol Nutr. 1996;23(3):280-286.

15. Tana C, Umesaki Y, Imaoka A, Handa T, Kanazawa M, Fukudo S. Altered profiles of intestinal microbiota and organic acids may be the origin of symptoms in irritable bowel syndrome. Neurogastroenterol Motil. 2010;22(5):512-519, e114-e115. 
16. Morken MH, Valeur J, Norin E, Midtvedt T, Nysæter G, Berstad A. Antibiotic or bacterial therapy in post-giardiasis irritable bowel syndrome. Scand J Gastroenterol. 2009;44(11):1296-1303.

17. Weaver GA, Krause JA, Miller TL, Wolin MJ. Short chain fatty acid distributions of enema samples from a sigmoidoscopy population: an association of high acetate and low butyrate ratios with adenomatous polyps and colon cancer. Gut. 1988;29(11):1539-1543.

18. El Oufir L, Flourie B, Bruley des Varannes S, et al. Relations between transit time, fermentation products, and hydrogen consuming flora in healthy humans. Gut. 1996;38(6):870-877.

19. Schwiertz A, Taras D, Schafer K, et al. Microbiota and SCFA in lean and overweight healthy subjects. Obesity (Silver Spring). 2010;18(1): 190-195.

20. Sadik R, Bjornsson E, Simren M. The relationship between symptoms, body mass index, gastrointestinal transit, and stool frequency in patients with irritable bowel syndrome. Eur J Gastroenterol Hepatol. 2010; 22(1):102-108.

21. Clausen MR, Bonnen H, Tvede M, Mortensen PB. Colonic fermentation to short-chain fatty acids is decreased in antibiotic-associated diarrhea. Gastroenterology. 1991;101(6):1497-1504.

22. Mortensen PB, Andersen JR, Arffmann S, Krag E. Short-chain fatty acids and the irritable bowel syndrome: the effect of wheat bran. Scand J Gastroenterol. 1987;22(2):185-192.

23. Talley NJ, Weaver AL, Zinsmeister AR, Melton LJ 3rd. Self-reported diarrhea: what does it mean? Am J Gastroenterol. 1994;89(8): 1160-1164.

24. Duncan SH, Belenguer A, Holtrop G, Johnstone AM, Flint HJ, Lobley GE. Reduced dietary intake of carbohydrates by obese subjects results in decreased concentrations of butyrate and butyrateproducing bacteria in feces. Appl Environ Microbiol. 2007;73(4): 1073-1078.

25. Scheppach W, Fabian C, Sachs M, Kasper H. The effect of starch malabsorption on fecal short-chain fatty acid excretion in man. Scand J Gastroenterol. 1988;23(6):755-759.

26. Perry GH, Dominy NJ, Claw KG, et al. Diet and the evolution of human amylase gene copy number variation. Nat Genet. 2007;39(10): 1256-1260.

27. Cann PA, Read NW, Cammack J, et al. Psychological stress and the passage of a standard meal through the stomach and small intestine in man. Gut. 1983;24(3):236-240.
28. Lillestøl K, Helgeland L, Arslan Lied G, et al. Indications of 'atopic bowel' in patients with self-reported food hypersensitivity. Aliment Pharmacol Ther. 2010;31(10):1112-1122.

29. Rozovsky A, Zheng B, Metha D, Lebenthal E, Dinoso VP. Alpha glucosidase deficiencies as a possible cause of irritable bowel syndrome (IBS). Gastroenterology. 1993;104:A276.

30. Lind R, Olafsson S, Hjelland I, Berstad A, Lied GA. Lifestyle of patients with self-reported food hypersensitivity differ little from controls. Gastroenterol Nurs. 2008;31(6):401-410.

31. Kassinen A, Krogius-Kurikka L, Makivuokko H, et al. The fecal microbiota of irritable bowel syndrome patients differs significantly from that of healthy subjects. Gastroenterology. 2007;133(1):24-33.

32. Balsari A, Ceccarelli A, Dubini F, Fesche E, Poli G. The fecal microbial population in the irritable bowel syndrome. Microbiologica. 1982;5(3): 185-194.

33. Cardona ME, Midtvedt T, Norin E. Probiotics in gnotobiotic mice: Short-chain fatty acids production in vitro and in vivo. Scand J Lab Anim Sci. 2001;28(2):75-84.

34. Makras L, Falony G, Van der Meulen R, De Vuyst L. Letter to the editor. J Appl Microbiol. 2006;100:1388-1389.

35. Bourdu S, Dapoigny M, Chapuy E, et al. Rectal instillation of butyrate provides a novel clinically relevant model of noninflammatory colonic hypersensitivity in rats. Gastroenterology. 2005;128(7):1996-2008.

36. Vanhoutvin SA, Troost FJ, Kilkens TO, et al. The effects of butyrate enemas on visceral perception in healthy volunteers. Neurogastroenterol Motil. 2009;21(9):952-957, e76.

37. Born P, Bauch C, Ulm K, Kamereck K, Classen M, Scheppach W. Fecal bacterial activity in symptomatic carbohydrate malabsorption: effect on the fecal short-chain fatty acid ratio. $Z$ Gastroenterol. 2000;38(8):623-626.

38. Dapoigny M. Effect of butyrogenic fibers in IBS patients. Sep 9, 2008. Available from: http://www.clinicaltrials.gov./ct2/show/NCT0031488 6?term=NCT00314886\&rank=1. Accessed May 16, 2010.

39. Hamer HM, Jonkers D, Venema K, Vanhoutvin S, Troost FJ, Brummer RJ. Review article: the role of butyrate on colonic function. Aliment Pharmacol Ther. 2008;27:104-119.

40. Chey WD, Nojkov B, Rubenstein JH, Dobhan RR, Greenson JK, Cash BD. The yield of colonoscopy in patients with non-constipated irritable bowel syndrome: results from a prospective, controlled US trial. Am J Gastroenterol. 2010;105(4):859-865.
Clinical and Experimental Gastroenterology

\section{Publish your work in this journal}

Clinical and Experimental Gastroenterology is an international, peerreviewed, open access journal, publishing all aspects of gastroenterology in the clinic and laboratory, including: Pathology, pathophysiology of gastrointestinal disease; Investigation and treatment of gastointestinal disease; Pharmacology of drugs used in the alimentary tract;

\section{Dovepress}

Immunology/genetics/genomics related to gastrointestinal disease. This journal is indexed on CAS. The manuscript management system is completely online and includes a very quick and fair peer-review system. Visit http://www.dovepress.com/testimonials.php to read real quotes from published authors. 